\title{
Differences of microscopic seepage mechanisms of water flooding and polymer flooding and prediction models of final oil recovery for conglomerate reservoir
}

\author{
Fengqi Tan ${ }^{1,2,}{ }^{*}$, Changfu Xu ${ }^{3}$, Yuliang Zhang ${ }^{3}$, Gang Luo ${ }^{1,2}$, Yukun $\mathrm{Chen}^{3}$, and Wentao $\mathrm{Liu}^{3}$ \\ ${ }^{1}$ College of Earth and Planetary Sciences, University of Chinese Academy of Sciences, Beijing 100049, China \\ ${ }^{2}$ Key Laboratory of Computational Geodynamics, CAS, Beijing 100049, China \\ ${ }^{3}$ Research Institute of Petroleum Exploration and Development, Xinjiang Oilfield Company, PetroChina, Karamay, \\ Xinjiang 834000, China
}

Received: 16 June 2018 / Accepted: 5 November 2018

\begin{abstract}
The special sedimentary environments of conglomerate reservoir lead to pore structure characteristics of complex modal, and the reservoir seepage system is mainly in the "sparse reticular-non reticular" flow pattern. As a result, the study on microscopic seepage mechanism of water flooding and polymer flooding and their differences becomes the complex part and key to enhance oil recovery. In this paper, the actual core samples from conglomerate reservoir in Karamay oilfield are selected as research objects to explore microscopic seepage mechanisms of water flooding and polymer flooding for hydrophilic rock as well as lipophilic rock by applying the Computed Tomography (CT) scanning technology. After that, the final oil recovery models of conglomerate reservoir are established in two displacement methods based on the influence analysis of oil displacement efficiency. Experimental results show that the seepage mechanisms of water flooding and polymer flooding for hydrophilic rock are all mainly "crawling" displacement along the rock surface while the weak lipophilic rocks are all mainly "inrushing" displacement along pore central. Due to the different seepage mechanisms among the water flooding and the polymer flooding, the residual oil remains in hydrophilic rock after water flooding process is mainly distributed in fine throats and pore interchange. These residual oil are cut into small droplets under the influence of polymer solution with stronger shearing drag effect. Then, those small droplets pass well through narrow throats and move forward along with the polymer solution flow, which makes enhancing oil recovery to be possible. The residual oil in weak lipophilic rock after water flooding mainly distributed on the rock particle surface and formed oil film and fine pore-throat. The polymer solution with stronger shear stress makes these oil films to carry away from particle surface in two ways such as bridge connection and forming oil silk. Because of the essential attributes differences between polymer solution and injection water solution, the impact of Complex Modal Pore Structure (CMPS) on the polymer solution displacement and seepage is much smaller than on water flooding solution. Therefore, for the two types of conglomerate rocks with different wettability, the pore structure is the main controlling factor of water flooding efficiency, while reservoir properties oil saturation, and other factors have smaller influence on flooding efficiency although the polymer flooding efficiency has a good correlation with remaining oil saturation after water flooding. Based on the analysis on oil displacement efficiency factors, the parameters of water flooding index and remaining oil saturation after water flooding are used to establish respectively calculation models of oil recovery in water flooding stage and polymer flooding stage for conglomerate reservoir. These models are able to calculate the oil recovery values of this area controlled by single well control, and further to determine the oil recovery of whole reservoir in different displacement stages by leveraging interpolation simulation methods, thereby providing more accurate geological parameters for the fine design of displacement oil program.
\end{abstract}

\section{Introduction}

More than 50 years' water flooding recovery has made the conglomerate reservoir in Karamay oilfield a high water

\footnotetext{
* Corresponding author: tanfengqi@ucas.ac.cn
}

saturation reservoir with a more than $85 \%$ water saturation rate (Zhu et al., 2015), which makes it hard to achieve a constant oil production by continuing the water replacement. Keeping water replacement will lead to a continue increasing of the water saturation rate in the reservoir and a sharp decrease in the oil production from the reservoir 
due to the very limited water flooding swept volume. Therefore, carrying out the polymer flooding as the third time exploration approach is going to be a major trend in the near future. The basic idea of polymer flooding is to replace water with the polymer as injection liquid to minimize the water phase permeability and maximum the injection liquid swept volume, which makes the increase in production rate possible (Jiang et al., 2014; Liu et al., 2014). By virtue of a more than thirty years' polymer flooding development experience in China, the application in Daqing oilfield has achieved a significant result (Wang et al., 2005). However, most research and application of polymer flooding are conducted in sand rock reservoir but are very limited in the conglomerate reservoir (Editorial Board of Science and Technology Books in Daqing Oilfield, 1998). For the reasons above, in year 2014 the Kexia group reservoir in No. 1 Area of East 7th Block of Karamay oilfield is selected as the experimental area for conglomerate oil reservoir polymer flooding project, expecting to explore the basic geology problems like microscopic seepage mechanism of polymer flooding, the configuration rules among CMPS of conglomerate reservoir and polymer molecular weight, and remaining oil after polymer flooding distribution features and further to provide geology background information for specific polymer flooding design.

For the purpose of the maximizing the oil production rate and guarantee a sustainable exploitation, the in-depth research on microscopic seepage mechanism of polymer flooding is both the foundation and precondition not matter for flooding reservoir or conglomerate reservoir (Meybodi et al., 2011). The special sedimentary environment of conglomerate reservoir such as near rock source, multiple watershed and rapid changing condition lead to the features of severer heterogeneity, more complex pore structure, smaller throat diameter, bigger pore-throat ratio, lower pore-throat coordination number and poorer hole connectivity (Hu et al., 1997; Tan et al., 2010). Therefore, the microscopic seepage mechanisms of polymer flooding and water flooding for sand rock oil reservoir are not suitable for conglomerate oil reservoir. Although Xu et al. have conducted series NMR-based experiments to compare the pore structure status and remaining oil distribution features in conditions of before and after water flooding, the research on polymer flooding condition is still in its initial stage so far (Xu et al., 2011). There are very limited researches on the differences of seepage mechanisms of polymer flooding and water flooding, the key oil replacement efficiency parameters, and the prediction models of oil recovery.

In the research of conglomerate reservoir, the microscopic seepage mechanism of polymer flooding, Liu et al. make use of the mercury intrusion method to address the configuration relationship between polymer in different molecular weight and the pore structure of conglomerate oil reservoir (Liu et al., 2008). Hu et al. conducted the research on pore structure within the conglomerate reservoir and its impacts on the remaining oil after polymer flooding (Hu et al., 2014). Feng et al. addressed the remaining oil distribution of features by modeling the polymer flooding process based on transparent microscopic experiments (Feng et al., 2007). All these research achievements mentioned above give a good start on the polymer flooding within the conglomerate reservoir, however, they also had their limitations mainly in two aspects. One is that most experiments can only measure the physical parameters of flooding liquid before and after core flooding instead of quantitative monitoring the liquid seepage process within the rock, which leaves the seepage mechanism still unknown. The other is that most flooding experiments select the artificial rock or the simulation model as the experimental subject which has remarkable feature differences with rocks in the real anisotropy conglomerate oil reservoir, thus not able to represent a real pore structure information of the reservoir and a comprehensive seepage mechanism. The Computed Tomography (CT) scan technology makes it possible to observe seepage status of the different type of flooding liquid in different displacement volume dynamically without changing outer shape and inner structure of the core sample. This technology with its unique advantages in acquiring fluid distribution information along axial direction within rock core, directly revealing the microscopic seepage mechanism, and locating the remaining oil distribution features inside the rock core has effectively reduced result errors from other experiments (Wang et al., 1985; Wellington and Vinegar, 1987; Xu et al., 2005). Therefore, by selecting conglomerate oil reservoir in Karamay oilfield as the research subject and leveraging CT scan technology, the authors try to analyze the differences of seepage mechanisms for two displacement types and locate remaining oil distribution features based on axial changing information of oil saturation, establish respectively two final oil recovery forecasting models for polymer flooding and water flooding, and further to provide technical support for polymer flooding project design.

\section{Conglomerate reservoir features}

The Karamay oilfield locates at northwestern margin of Junggar basin in where the typical conglomerate oil reservoirs development in this area, the Zaire mountain steadily supply a large amount of sedimentary sources and the rock source direction have good succession (Li et al., 1997). Overall the sedimentary environment of conglomerate oil reservoir in research area belongs to alluvial fan and gravelly braided fluvial facies (Fig. 1). The No. 1 Area of East 7th Block is cut into similar rhombus sealed fault-block reservoir by surrounding faults and the regional structure is a southeast-dipping monoclinic, the Kexia group formation in this area is a set of positive cycle glutinite deposit of piedmont alluvial fan which coves above weathering crust of Paleozoic metamorphic (Wei et al., 2007), the formation thickness is $60 \sim 120 \mathrm{~m}$. The reservoir lithologies are mainly conglomeratic gritstone, glutenite and conglomerate, the compositional maturity and textural maturity of these rocks are both poor, the average values of effective porosity and effective permeability are respectively $19.6 \%$ and $395.1 \times 10^{-3} \mu \mathrm{m}^{2}$, overall it belongs to a middle porosity and high permeability oil reservoir.

The special sedimentary environment of conglomerate reservoir leads to following reservoir features such as severe 


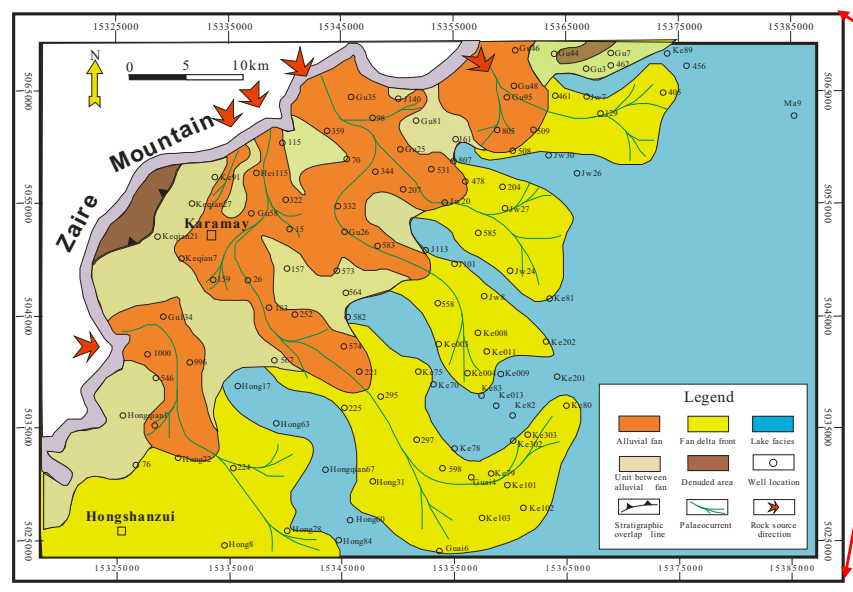

(A)

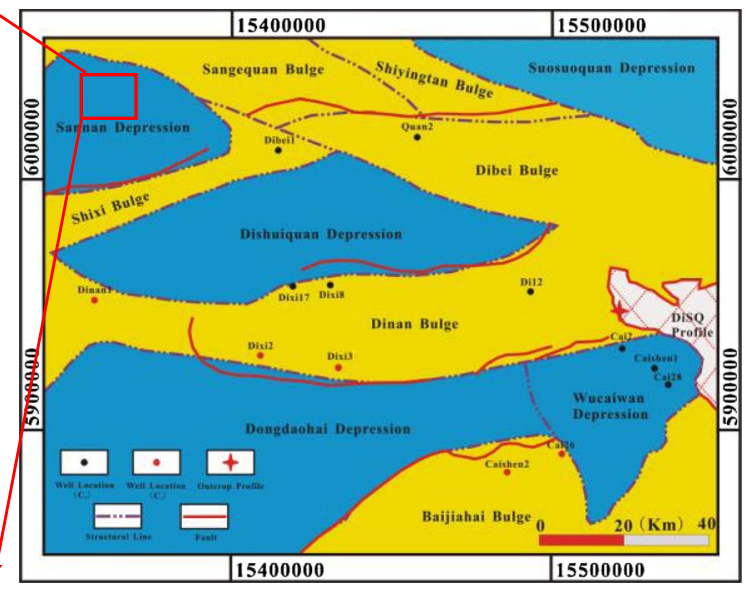

(B)

Fig. 1. Structural units and sedimentary distribution of conglomerate reservoir in research area. (A) Sedimentary distribution in research area. (B) Structural units in Junggar basin.

Modals

Fig. 2. Comparison chart of pore structure of clastic reservoirs.

heterogeneity, CMPS and sparse reticular or non reticular seepage system (Luo, 1991; Luo and Zhang 1992). From Figure 2, we can see that typical sand reservoir is generally single modal pore structure which have following features such as good particle sorting, low matrix content, uniform particle size and pore-throat distribution, these features can make sand reservoir to form better pore network system. During water flooding process of oil reservoir, it is easy to form network seepage channels to expand water flooding swept volume and improve water displacement oil efficiency, the whole oil reservoir performs uniform water displacement oil characteristic (Dullien, 1979). Generally, the double modal reservoir is mainly conglomerate (sand) structure which main components include to fine-grained conglomerate and part of sandy conglomerate, the conglomerate (sand) particles make support parts to form rock frame and argillaceous fill between rock frame. This type of reservoir has following features such as poor particle 
sorting and uneven pore-throat distribution which easily lead to sever water channeling during water displacement oil process, then the water flooding swept volumes are mainly large pore and wide throat and the water ratio highly increase, above production features can lead to low water displacement oil efficiency (He et al., 2012).

However, the typical conglomerate oil reservoir performs CMPS feature, its variation range of particle size is more wide and pore structure is more complex because the shale content is higher and gravel particles suspended in sand and shale, and the pore-throat distribution is also more uneven. At present, the research on microscopic seepage mechanisms of polymer flooding of conglomerate reservoir is very less by domestic and foreign experts, so for this type of reservoir the study on microscopic seepage mechanisms of water flooding and polymer flooding and their differences become geological basis of enhancing oil recovery, and is also the important contents of complementing seepage mechanisms of clastic reservoirs.

\section{Sample selection and experimental steps}

\subsection{Experimental sample selection}

The rock cores for this experiment are taken from two typical conglomerate samples which belong to Kexia group formation of well T71721 in No. 1 Area of East 7th Block. One of the original conglomerate samples indicates hydrophilic type, with the diameter of $11.5 \mathrm{~cm}$, a length of $40 \mathrm{~cm}$ and taken the depth of $1077.4 \mathrm{~m}$. The other one indicates weak lipophilic type, with a diameter of $11.5 \mathrm{~cm}$, a length of $50 \mathrm{~cm}$ and taken the depth of $1098.8 \mathrm{~m}$. For the purpose of better understanding how the conglomerate reservoir pore structure would affect the seepage mechanism, the analysis of the micro microscopic seepage mechanism features on both core samples is made. Analysis results show that the hydrophilic core sample belongs to conglomerate rock type with $28.6 \%$ porosity and $1419 \times$ $10^{-3} \mu \mathrm{m}^{2}$ air permeability. The reservoir minerals mainly consist of quartz and plagioclase, with some of feldspar and also with small parts of calcite, ankerite and siderite. This core sample has a well-developed interparticle pore and the lamellar and shape collection kaolinite interstitial, the interstitial materials are mainly in the form of argillaceous heteroaryl, clay mineral and plastic hydromica etc. (Fig. 3A). Compared to the hydrophilic sample, the weak lipophilic core sample has same mineral components, but belongs to conglomeratic gritstone type with $24.2 \%$ porosity and $1501 \times 10^{-3} \mu \mathrm{m}^{2}$ air permeability, the interstitial materials are mainly in the form of argillaceous heteroaryl, clay mineral and chloritization mica debris etc. It also has a well-developed interparticle pore which is filled in authigenic clay mineral and small parts of fine intraparticle pore (Fig. 3B).

\subsection{Experimental condition}

1. Experimental equipment. The scan system is 8-slice spiral CT equipment of SOMATOM Spirit, the scan voltage and electric current are respectively $100 \mathrm{kV}$ and $120 \mathrm{~mA}$, scan thickness is $1 \mathrm{~mm}$ and rebuild time of scan images is $0.16 \mathrm{~s}(1024 \times 1024$ matrix $)$.

2. Experiment liquid. Crude oil: selected from the Kexia group reservoir with $65 \mathrm{mPa}$ s viscosity under $35^{\circ} \mathrm{C}$ in No. 1 Area of East 7th Block. Displacing water: same as the flooding water used from the Kexia group reservoir in No. 1 Area of East 7th Block, the water type is $\mathrm{CaCl}_{2}$ and its mineralization rate is $365.4 \mathrm{mg} / \mathrm{L}$. Displacing polymer: the polyacrylamide with 25 million molecular weight is selected to form solution compound with water and the concentration is $1200 \mathrm{mg} / \mathrm{L}$, which is the optimal experimental result based on the conglomerate reservoir polymer flooding research.

3. Experimental settings. Displacement speed: $0.05 \mathrm{~mL} /$ min, temperature: the same as the temperature of Kexia group reservoir which is $35^{\circ} \mathrm{C}$.

\subsection{Experimental steps}

Totally five steps: (1) scan the two samples cores under dry condition and determine the heterogeneity degree of CMPS based on the horizontal and vertical CT value; (2) scan the two samples cores that are saturated with original formation water and to calculate the average porosity and its vertical distribution, then further to establish the $3 \mathrm{D}$ pore distribution features of the sample core; (3) make use of the pressurized gradient method to displace the water with crude oil and make sure the water is in bound-water status within core sample. After that, the bound water distribution features and average bound water saturation can be determined, which can be used as parameters to further calculate the axial distribution information of original oil saturation and the average original oil saturation of the both samples; (4) start the water displacement experiment by injecting water at a speed of $0.05 \mathrm{~mL} / \mathrm{min}$ and scan the core sample using the Pore Volume Injection (PVI) as the standards to get the axial distribution information of oil and water saturation, until the water content rate of the outlet liquid reaches $98 \%$ to stop; (5) after the water displacement, repeat the process by using polymer at the same speed until no oil contained in the outlet liquid to stop the experiment.

\section{Experimental results and its analysis}

\subsection{Sample heterogeneity and liquid distribution characteristics}

Based on the 3D images of different pore volume from CT scan results of two samples, combined with the porosity axial distribution information, it can be found that the hydrophilic sample has severe heterogeneity features of pore structure and poor pore connection in different porosity range, and the change width of porosity axial distribution curves is also large, above characteristics indicate that the pore structure of hydrophilic sample is more complex. On the other hand, the weak lipophilic sample shows features of relative weak heterogeneity of pore structure and 

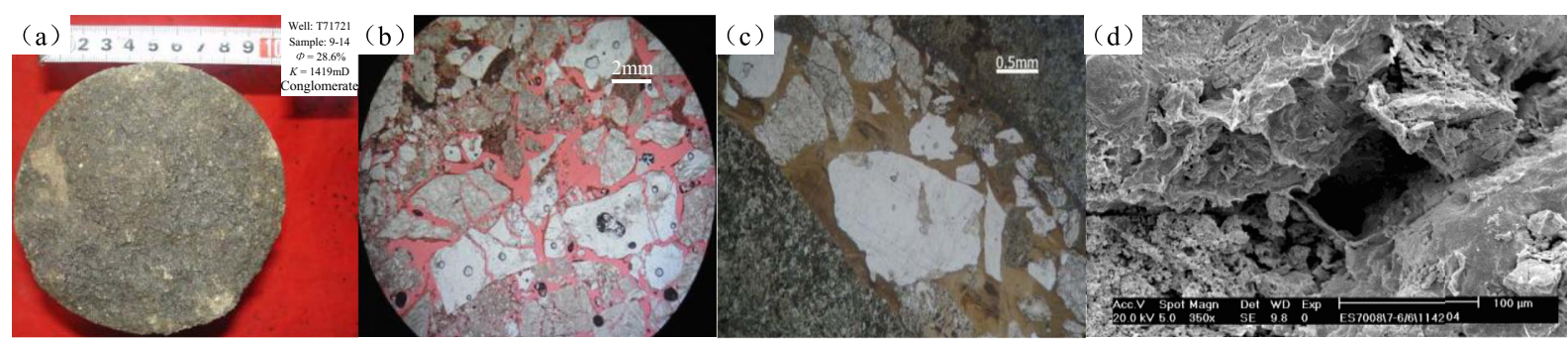

(A)

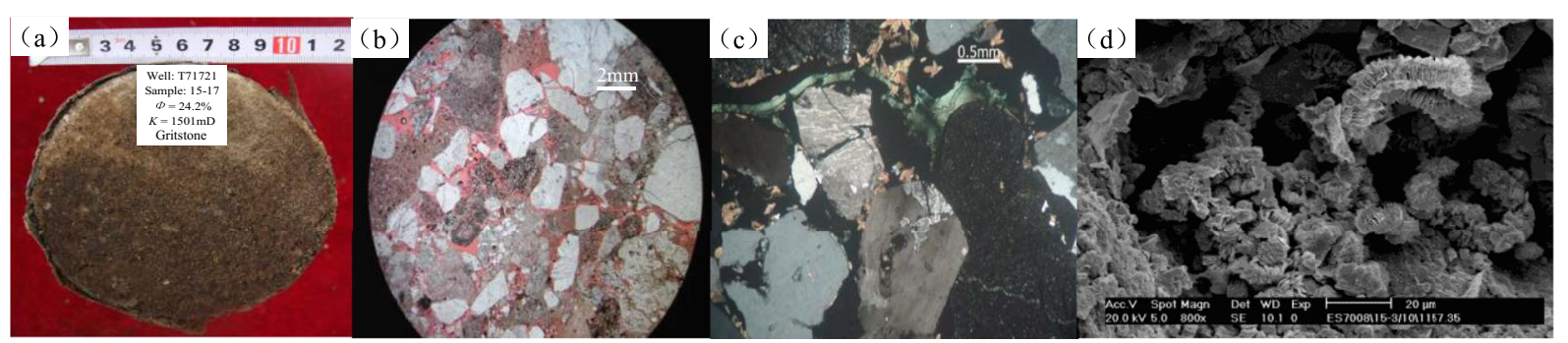

(B)

Fig. 3. Comparison chart of micro-pore structure of experimental samples. (A) Hydrophilic sample; (B) Weak lipophilic sample.

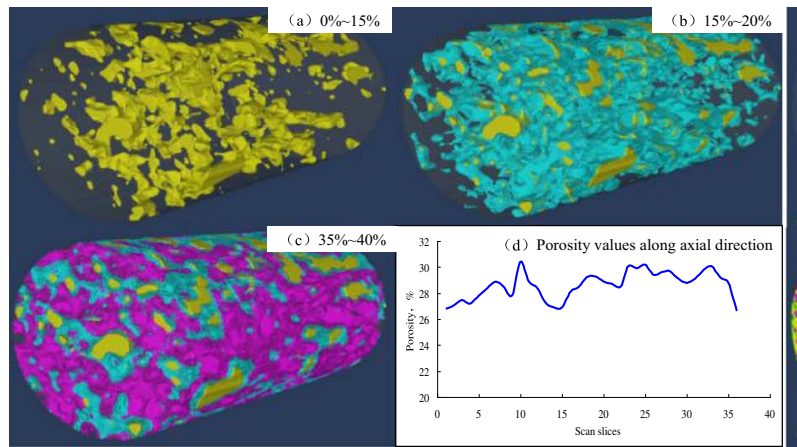

(A)

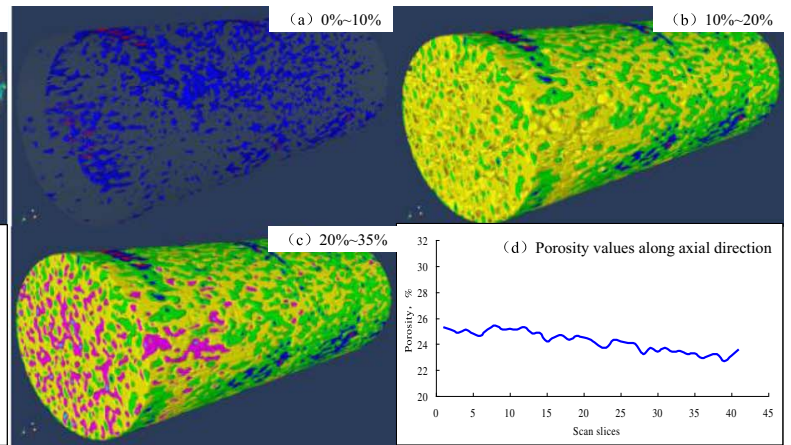

(B)

Fig. 4. Porosity 3D reconstruction and axial distributions of experimental samples. (A) Hydrophilic sample; (B) Weak lipophilic sample.

good pore connection in different porosity range, the change width of porosity axial distribution curves is smooth, so its pore structure is better than hydrophilic sample (Fig. 4). In addition, the physical property comparison also directly shows that although the porosity $(28.6 \%)$ of hydrophilic sample is significantly larger than the porosity $(24.2 \%)$ of the lipophilic sample, the permeability $\left(1419 \times 10^{-3} \mu \mathrm{m}^{2}\right)$ of the former is smaller than the permeability $\left(1501 \times 10^{-3} \mu \mathrm{m}^{2}\right)$ of the later. Therefore, the pore structure and the pore connection status play the key role in determining the permeability of conglomerate reservoir with severe heterogeneity.

Based on the bound water model of two core samples, the axial distribution information of the original oil saturation can be determined. The total 36 scanned slices from hydrophilic sample indicate average $55.1 \%$ oil saturation and the total 42 scanned slices from weak lipophilic sample indicate average $64.4 \%$ oil saturation (Fig. 5). The complex pore structure plays the key role in controlling liquid distribution features of severe heterogeneity conglomerate reservoir in the following three aspects according to the 3D images of pore structures. Firstly, the hydrophilic sample has a more complex pore structure than the lipophilic sample and a $9.3 \%$ lower original oil saturation than the lipophilic sample. Secondly, the axial distributions of original oil saturation in both core samples show a complex change trend in the curve. The curve is in a flat "U" shape for hydrophilic sample and in a general " $n$ " shape with multiple small peaks for weak lipophilic sample. Thirdly, there is large change width of the axial distribution curves in both samples in the rate as high as to $17 \%$ and $33 \%$ respectively. 


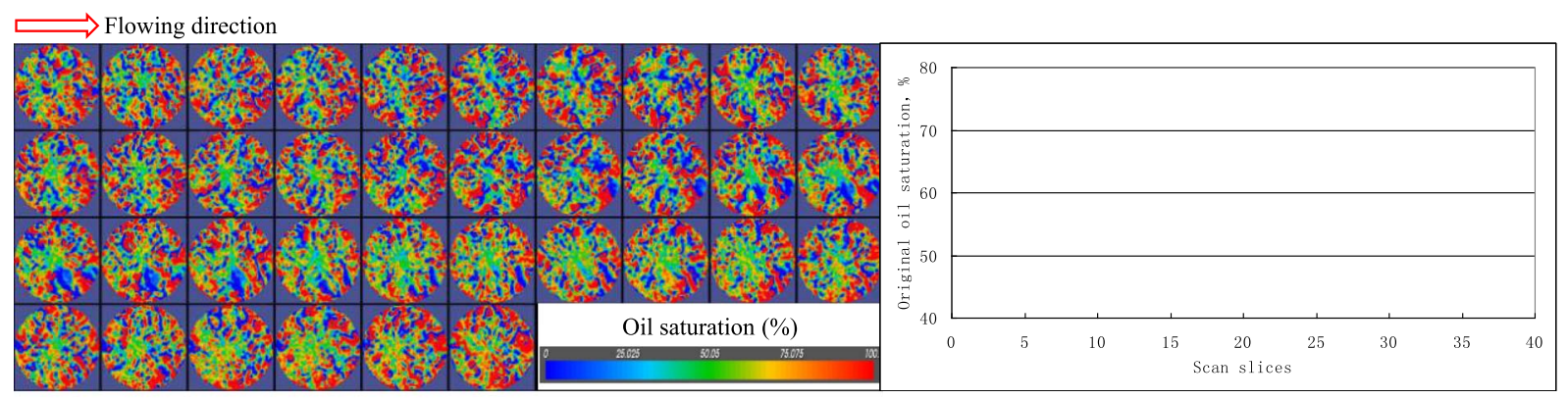

(A)
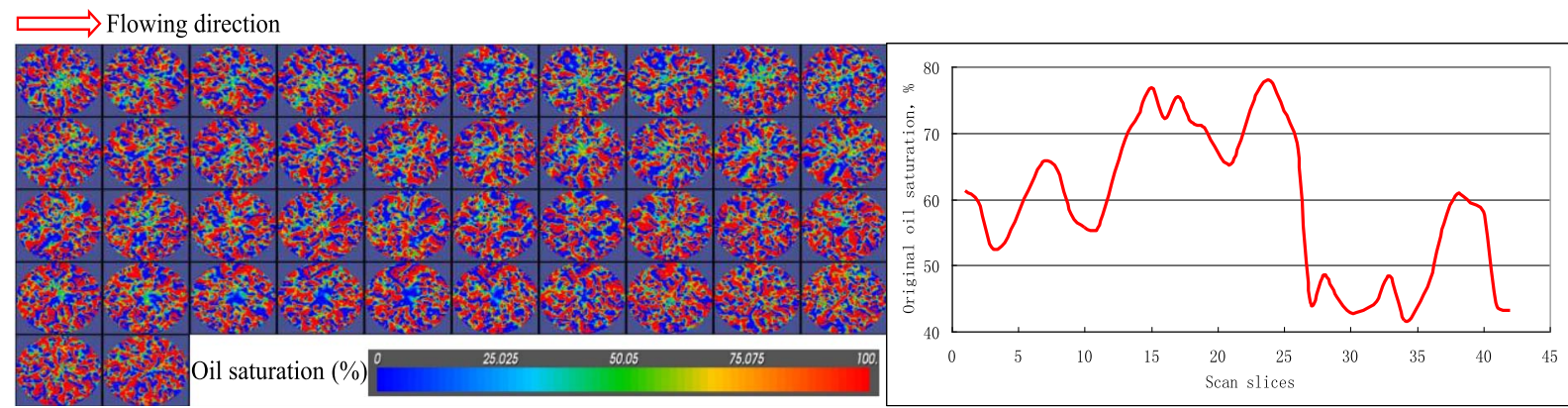

(B)

Fig. 5. Axial distributions of original oil saturation of experimental samples. (A) Hydrophilic sample; (B) Weak lipophilic sample.

\subsection{Displacement mechanism and remaining oil distribution of hydrophilic sample}

\subsubsection{Water flooding mechanism and remaining oil distribution characteristics}

During the water flooding process, the injection water follows different seepage mechanisms while entering the pores in core samples because of different pore structure and different wettability. The transparent pore model of microscopic simulation is made to study the seepage mechanisms of water flooding and polymer flooding for conglomerate reservoir. Firstly, the pore network on cast thin slice of conglomerate sample is copied by photolithography method, then the following steps such as plate making, gumming, photoimaging, chemical etch and sintering molding are completed to achieve the transparent pore model of microscopic simulation, this model size is $62 \mathrm{~mm} \times$ $62 \mathrm{~mm} \times 3.0 \mathrm{~mm}$. Finally, two small holes in model diagonal are punched in order to simulate injection well and production well. Based on the displacement images (Fig. 6A), the injection water flows through the pore and throat of hydrophilic sample in a "crawling" displacement along rock particle surface pattern. For the small pore and throat, the injection water is able to displace crude oil and saturate the all pore space in a short time. On the other hand, the injection water flowing pattern could vary in two patterns for larger pore and throat, one situation is the flow pattern in the large pore is the same as in the small pore and throat; the other situation is that the injection water flows along the path of water film sticking to the wall of the pore and leaves the oil in the center of the pores which becomes the residual oil.

For the sand reservoir with a relatively dense distributed flowing pore and throat, the liquid flows in a dense reticular flowing pattern, but for the conglomerate reservoir, the flowing pore is sparsely and unevenly distributed and some parts' effective pore coordination number are even less than 2, all of these features limited the formation of effective seepage system in the conglomerate reservoir. Therefore, the sparse reticular - non reticular becomes the main liquid flowing pattern of the conglomerate reservoir seepage mechanism. There are three features of this kind of hydrophilic conglomerate seepage mechanism: (1) Severe heterogeneity. The variation coefficient of pore-throat radius for conglomerate reservoir ranges from 5 to 15 while most are under 1 for the sand reservoir. The water displacement experiment obviously demonstrates that severe heterogeneity would lead to a priority flowing channel in the core sample. The CT scanning results shows that high seepage channels exist in the center and bottom part of the core sample which allows the injection water passing along fast while leaving the liquid flowing slowly in most other channels (Fig. 7A). The priority seepage flowing channel is going to exist obviously when the pore volume injected reaches $0.381 \mathrm{PV}$. In addition, severe heterogeneity would also lead to the lack of consistent water flooding front during water displacement process. Based on the axial distribution curves of reducing amount of oil saturation, it could be observed that there is a short lasting water flooding front when the PVI is between 0.016 and $0.047 \mathrm{PV}$ but it disappears as the increase of the PVI and the present of 


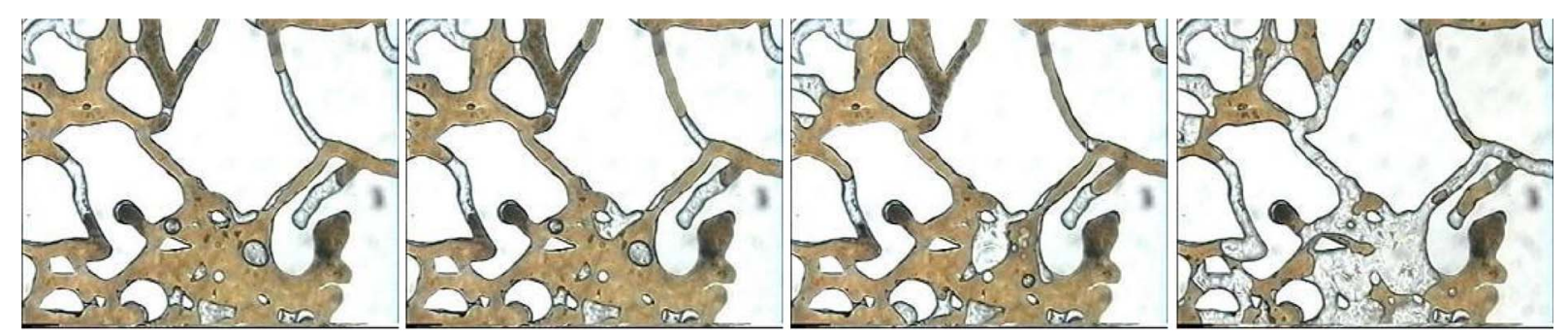

(A)
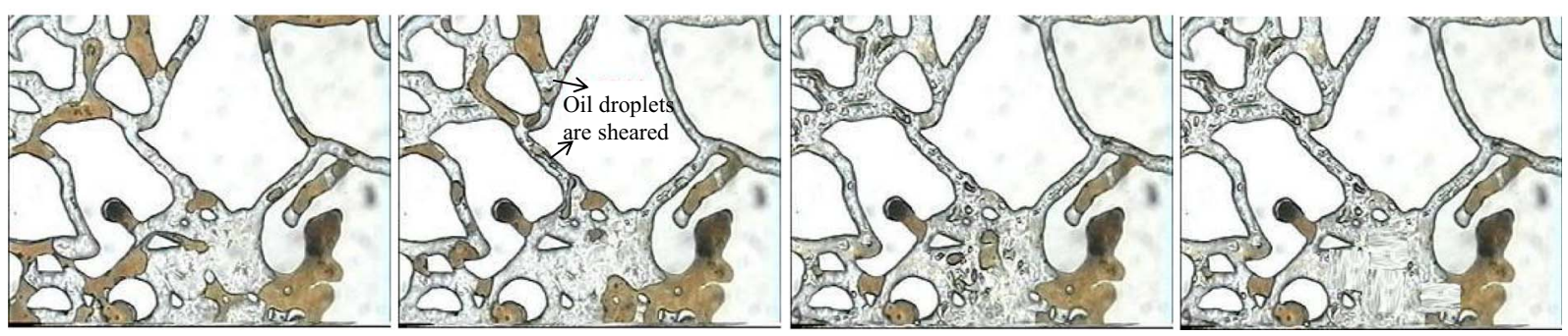

(B)

Fig. 6. Flooding mechanism by transparent pore model of microscopic simulation for hydrophilic sample. (A) Water flooding process; (B) Polymer flooding process.
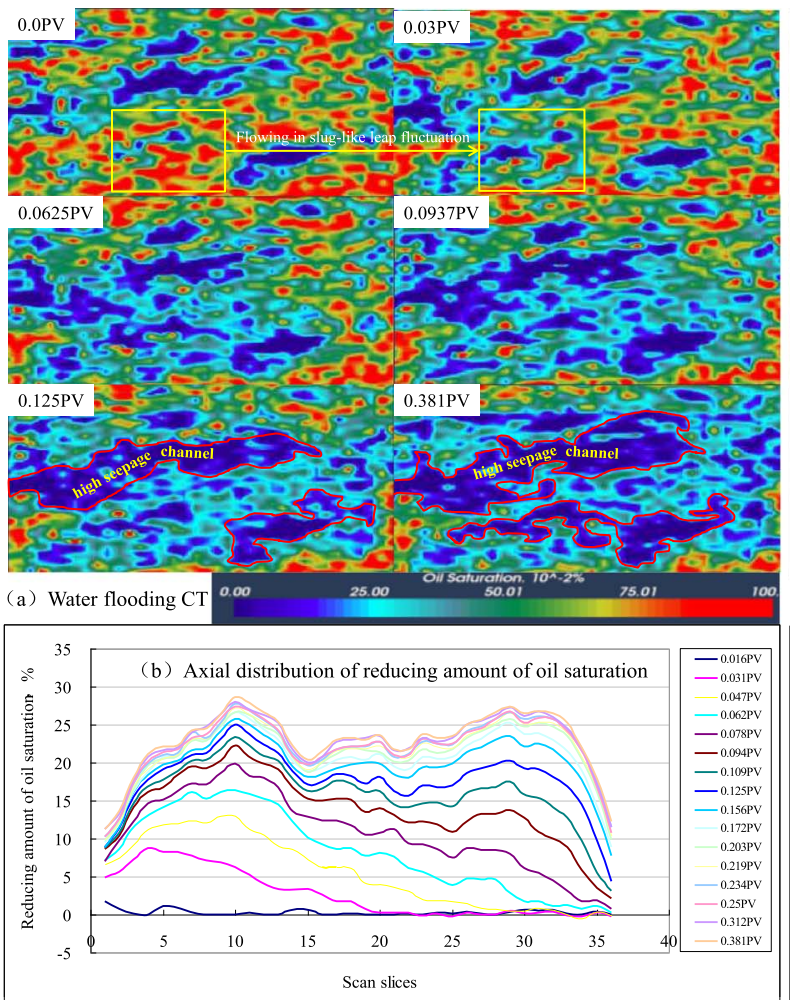

(A)
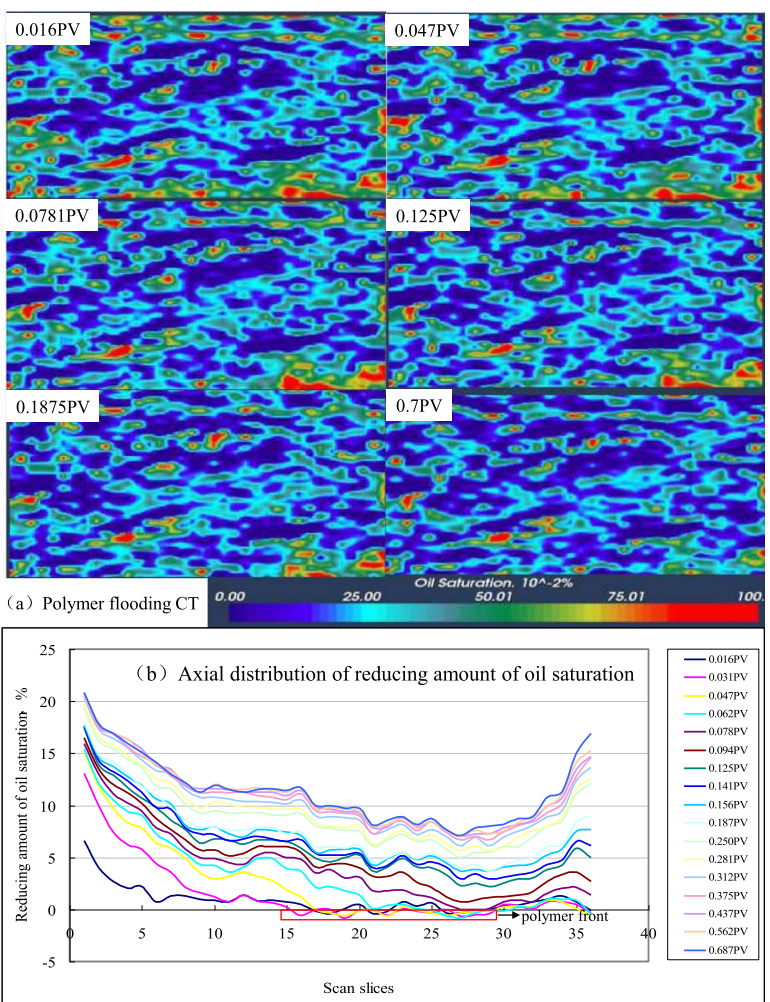

(B)

Fig. 7. CT scan images and axial distributions of reducing amount of oil saturation under different displacement conditions for hydrophilic sample. (A) Water flooding process; (B) Polymer flooding process. 
high seepage channel. (2) Significant displacement resistance effects. Large pore-throat diameter is the typical feature of conglomerate rock that could be multiple times or even hundred times larger than the diameter of sand rock. However, the following features of slim, tortuous, coarse and low pore coordination number have led to an obvious seepage resistance on the multiphase flowing of pore fluid. The micro water-oil displacement experiment has demonstrated the oil and water moves in a slug-like leap fluctuation formula for non-high seepage area when driven by water evenly (Fig. 7A). Affecting by the complex pore structures within core samples, the seepage resistance has a sharp increase when the flow tries to pass through the slim-small throat and put into next pore space. As a result, most liquid flows under less resistance channel to avoid the high resistance slim-small throat and the only very small amount of liquid can "scrawl" along the particle surface of hydrophilic rock, which leave some oil and form throat residual oil. (3) Low water flooding recovery. The general water flooding recovery is as low as $45.4 \%$ affecting by following factors such as uneven water onrush, surface tension retention and slim pore-throat breaking etc. For hydrophilic conglomerate core sample, the residual oil mainly distributes in the throat, the intersection of pores and the large pore that are surrounded by small pores in the form of oil droplets, oil leg and small oil clot within non displacement pore space.

\subsubsection{Polymer flooding mechanism and remaining oil distribution characteristics}

The mechanism of polymer flooding is to increase the injection liquid viscosity and decrease the water phase permeability by increasing polymer molecular weight and changing its concentration in order to decrease water-oil mobility ratio of whole displacement system, then achieve the final aim of enhancing oil recovery (Buchgraber et al., 2011; Wegner, 2015). The micro polymer flooding experiment shows that the polymer solution firstly enters the high permeability pores which saturated with full water along the pore wall, then move forward to pores with mid-low permeability for hydrophilic sample (Fig. 6B). In the polymer flooding experiment, the interfacial tension between polymer solution and crude oil is $0.012 \mathrm{~N} / \mathrm{m}$ and the interfacial tension between water and crude oil is $0.015 \mathrm{~N} / \mathrm{m}$, because the former is smaller than the latter, when the polymer liquid attaches to the pore wall the oil phase seepage resistance can be decreased, then the oil phase moving speed significantly increased. In addition, the polymer solution can increase the viscosity of oil-water interface, the feature of which allows for the easy transition of oil drops in the polymer saturated pores and the easy pass through the slim throat. Compared to the water flooding experiment results, the polymer flooding has a better displacing result for the water flooding residual oil trapped in the pores and throats with complex structures. In the rock level, the better results represent a higher displacing efficiency in slim throats and pores; less impact on polymer displacing channel by pore structures. In the production level, the better results represent in $20.8 \%$ higher oil recovery in polymer displacing $(66.2 \%)$ than water displacing $(45.4 \%)$.
Another significant advantage of polymer displacement is there existing a stable polymer flooding front in a low PVI (Batenburg and Oedai, 2013). Because the polymer displacement increases the pressure difference, it is possible to displace oil under high capillary force for the slim throat. The figure of axial distributions of the reducing amount of oil saturation (Fig. 7B) indicates that there is an obvious polymer front in a low PVI (0.016 0.062 PV). During the displacing process, the oil saturation in the injecting end of experimental sample reduced significantly, and the reducing amount of oil saturation in the exporting end is negative which indicate that the oil saturation in the pore volume of these scan slices increase to form a rich oil saturation area with continuous moving forward of polymer solution. As the PVI increasing, the advantage seepage channel by polymer displacement appears and comes along with the disappearance of polymer flooding front. This special micro seepage mechanism can be explained by the higher shear stress between polymer liquid and oil than the shear stress between water and oil. Because the polymer is a kind of synthetic substances which formed by the macromolecule of high molecular weight, the twining effect among polymer molecular can lead to viscosity increasing of polymer solution, and then it has the higher shear stress than water. Under the effect of shear stress between polymer liquid and oil, the large oil droplet stored in large pores are chopped into small droplets which continue to move forward with polymer liquid through the throat, which increases the residual oil carrying capacity of polymer liquid. However, the "sparse reticular and non reticular" pore structure of conglomerate reservoir does not allow this displacement pattern last long time till a new advanced seepage channel formed and comes with the disappearance of the polymer flooding front. As a result, no matter for water displacing or polymer displacing, the complex pore structures in conglomerate reservoir make the water onrush along advanced seepage channel and severe non-uniform displacement as the dominant displacing pattern.

\subsection{Displacement mechanism and remaining oil distribution of weak lipophilic sample}

\subsubsection{Water flooding mechanism and remaining oil distribution characteristics}

For the weak lipophilic sample, the injection water enters the pores in an inrushing pattern along the pore central and keeps inrushing throw pore axis of the whole displacing process, then finally forms an oil film on the pore wall. The thickness of the oil film is affected directly by the lipophilic level of the sample surface, although the oil film exists along all the pore surfaces. The phenomenon was called "inrushing seepage mechanism" caused by the non-wetting phase of the injecting water flowing through the lipophilic surface and wetting phase of oil, which is hugely different from the "scrawling seepage mechanism" of hydrophilic samples (Fig. 8A). By comparing the water displacement images between the lipophilic sample (Fig. 8A) and hydrophilic sample (Fig. 6A), it can be clearly found that while the injecting water inrushing though the pore central of the lipophilic sample, the crude oil in the pores is segregated 

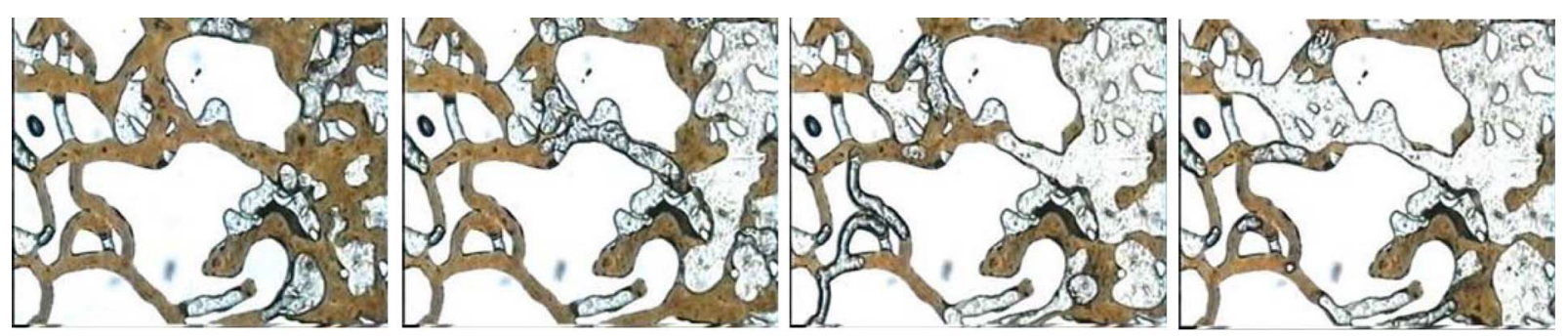

(A)
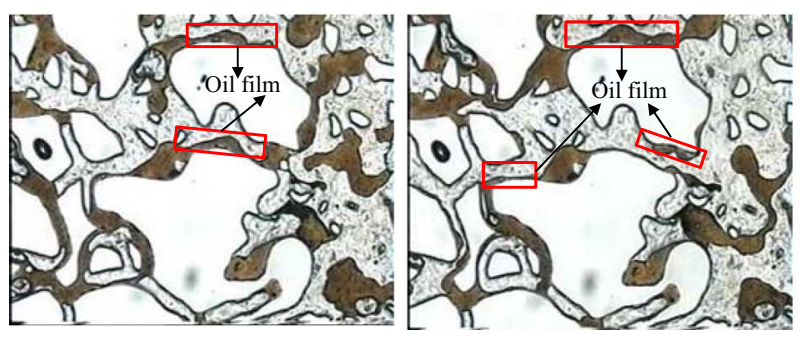
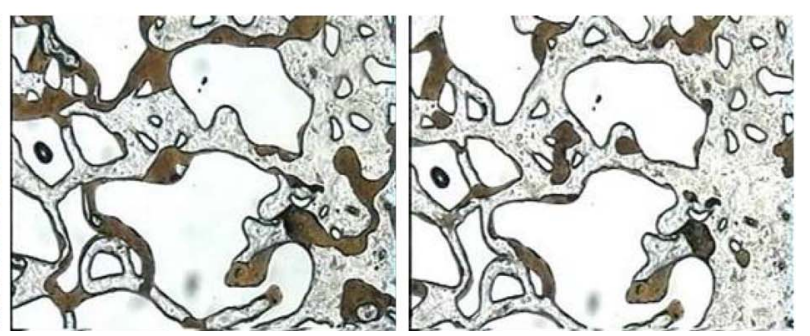

(B)

Fig. 8. Flooding mechanism by transparent pore model of microscopic simulation for lipophilic sample. (A) Water flooding process; (B) Polymer flooding process.

quickly into some parts. One part is carried away by injecting water and the other part was sliced into smaller oil remaining area. As the increasing of PVI of injecting water, the slicing process happens repetitively and more frequently which leads to the increase in the number of the amount of oil remaining areas, but a decrease in the total oil amount of each small oil remaining area. The water displacing process ends up with small oil droplets remaining evenly among the pores, which is different from the remaining oil features of hydrophilic samples. Thus, there are significant differences between the hydrophilic samples and lipophilic samples in aspects of the micro seepage mechanism, displacing pattern and remaining oil distribution features.

Because of the severe heterogeneity, it also lacks a stable water flooding front during the displacement process of weak lipophilic samples. Based on the axial distributions of reducing amount of oil saturation (Fig. 9A), there is not a temporal water flooding front like in the case of hydrophilic samples even in a low PVI because of the inrushing seepage mechanism. In addition, the severe heterogeneity of conglomerate reservoir will cause the difference of water flooding oil recovery for hydrophilic sample and weak lipophilic sample, the former value is $45.4 \%$ (Fig. 7A) and the latter value is $42.3 \%$ (Fig. 9A), so the water flooding oil recovery of weak lipophilic sample is $3.1 \%$ lower than the water flooding oil recovery of hydrophilic sample. Therefore, for different wettability conditions of the conglomerate reservoir, the difference of water displacing micro seepage mechanism will affect the final water flooding oil recovery while the oil recovery of the hydrophilic sample is generally higher than lipophilic sample. For the weak lipophilic sample, the remaining oil mainly distributes among the particle surface in the form of oil film, while the slim throat, throat end, and non-displacing oil area also become the enrichment region of residual oil.

\subsubsection{Polymer flooding mechanism and remaining oil distribution characteristics}

The micro polymer displacing experiment shows that the inrushing seepage is also the dominant seepage mechanism for weak lipophilic samples (Fig. 8B). When polymer solution and crude oil both flowing within the pores, polymer solution flows along the central axis of pore space while oil flows among the pore-throat wall. Different from displacement pattern of shearing and carrying away residual oil by polymer solution in hydrophilic samples, the oil film attached to the throat wall for weak lipophilic samples becomes the major channel for remaining oil moving because these connecting oil films can increase crude oil fluidity. The seepage mechanisms can be concluded into two types: (1) Oil film communication and flowing along pore wall. The unmovable residual oil attached to the pore wall starts moving towards the downstream direction along with pore wall carried by polymer solution and then gathered at the other side of rock particle. When the oil film attached to the pore wall accumulated to a certain amount, a "bridge" appears between rock particles that allow oil moving from upstream to downstream and further be exploited, which was also called "bridge effect" (Hua et al., 2016). Although this phenomenon looks similar to low interfacial tension phenomenon, the real observation documents indicate that there is not a significant difference between the interfacial tension between polymer solution and crude oil at $0.012 \mathrm{~N} / \mathrm{m}$ and the oil-water interfacial tension at $0.015 \mathrm{~N} / \mathrm{m}$. Thus, instead of determined by the interfacial tension difference, the seepage mechanism is determined by the higher shear stress between polymer liquid and oil than the shear stress between oil and water. (2) Formed oil silk. The oil film gathered at the particle surface of the weak lipophilic rock is dragged into long silk shape by 

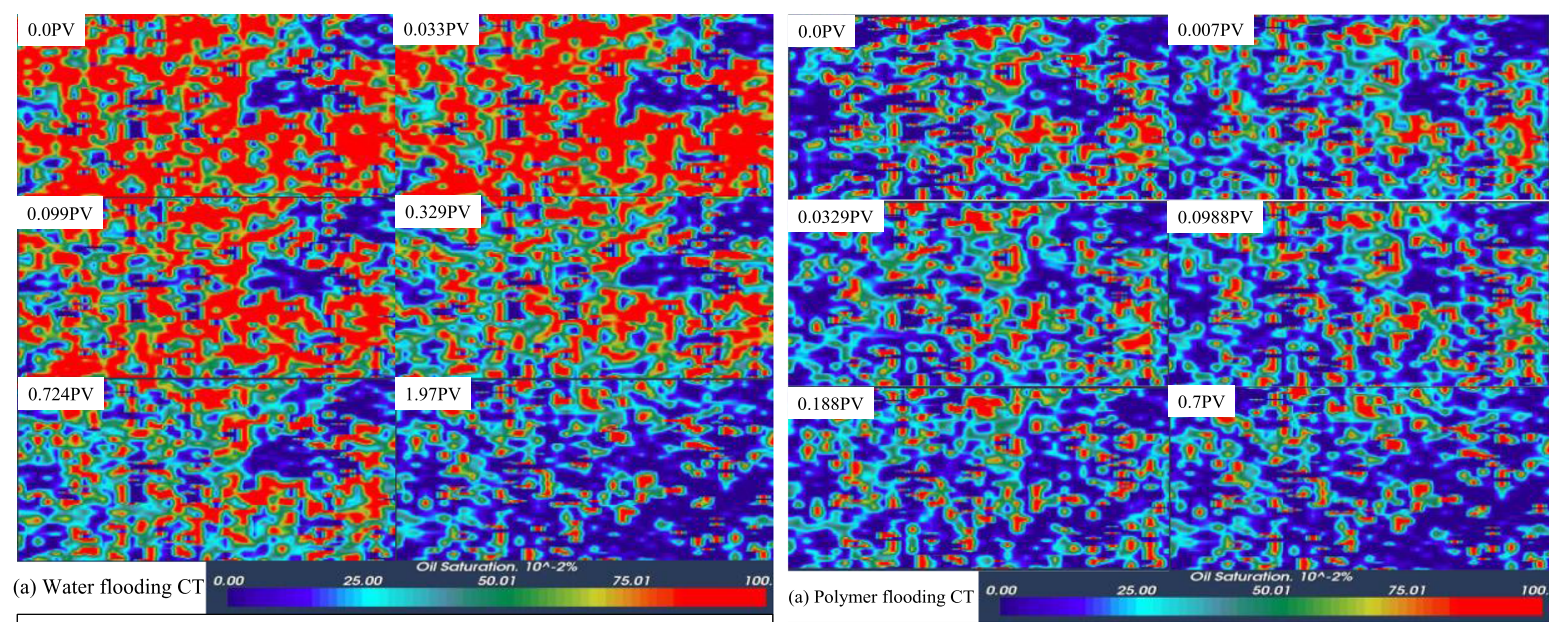

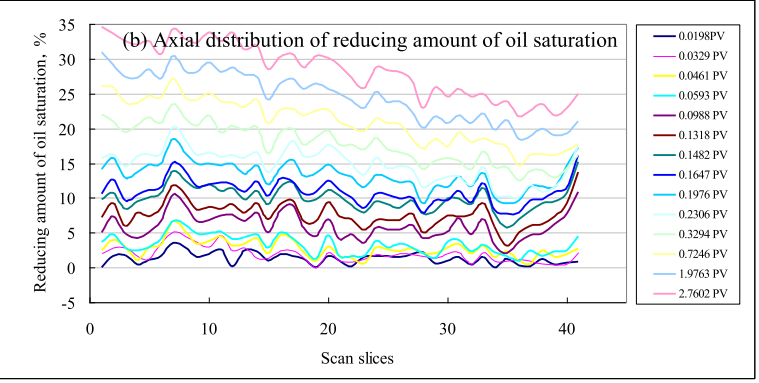

(A)

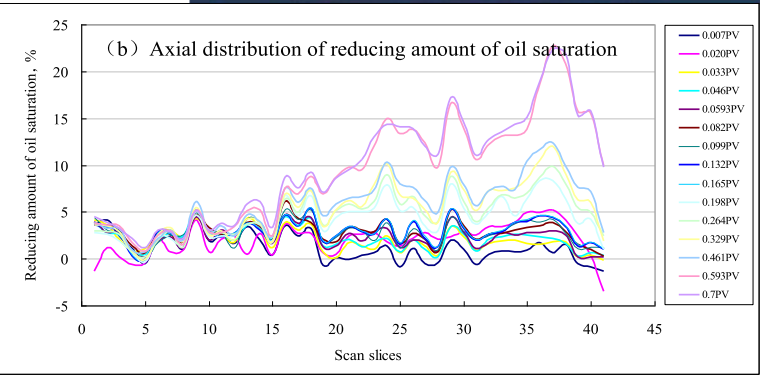

(B)

Fig. 9. CT scan and axial distributions of reducing amount of oil saturation by different displacement conditions for lipophilic sample. (A) Water flooding process; (B) Polymer flooding process.

polymer solution shear effect along the oil and water flowing direction. The silk shape oil swings and could be further dragged into small oil droplets when the polymer solution shear stress is strong enough. These droplets could be easily carried away by polymer solution to achieve the purpose of enhancing oil recovery.

The micro polymer displacing experiment (Fig. 9B) of weak lipophilic sample indicates that the amount of residual oil in the sample after polymer displacement is significantly smaller than the amount before polymer displacement, especially for residual oil in throats, only leaving some small oil droplets and thin oil film attached to the rock particle surface, the displacement effect is better. Most large oil plaque is carried away in pores, only leaving some small droplets in the crossing place of the throats. However, there is still a certain amount of residual oil staying in the shape throat and throat end where the polymer displacement result is not ideal. As a result, there still some amount of remaining oil in the reservoir after polymer displacement because of the rich throat end in the conglomerate reservoir. In general, the polymer displacement technology has an obvious effect on enhancing oil recovery in micro displacing experiments in which there is an $18.5 \%$ oil recovery increasing between the water displacement at $42.3 \%$ and the polymer displacement at $60.8 \%$. Based on above analysis, for the conglomerate reservoir with "sparse reticular and non reticular" pore structures, the inrushing seepage and oil film bridge are the two major seepage features for weak lipophilic samples both for water displacement and polymer displacement.

\section{Factors of oil displacement efficiency and oil recovery models}

Different displacement methods carried on the same oil and gas reservoir will cause the difference of oil displacement efficiency which will further affect the final oil recovery. Thus, the accurate prediction of oil recovery is the key to the high-efficiency reservoir development (Li et al., 2010). In general, the factors affecting oil displacement efficiency could be in aspects of external and internal (Alishaev and Belyanin, 1999; Li and Chen, 2006). The external factors mainly include injection pressure, displacing speed, polymer molecular weight, polymer solution concentration and so on. The internal factors mainly include reservoir properties, wettability and pore structures etc. This research focuses on the impacts of internal factors on oil displacing efficiency of polymer and water displacement respectively. The external parameters are selected based on the optimal results of other experiments for the research area, and which include the polyacrylamide with 25 million molecular weight, mass concentration of $1200 \mathrm{mg} / \mathrm{L}$ and displacement speed of $0.05 \mathrm{~mL} / \mathrm{min}$. After analyzing the factors of oil displacement efficiencies driven by water and polymer solution for 


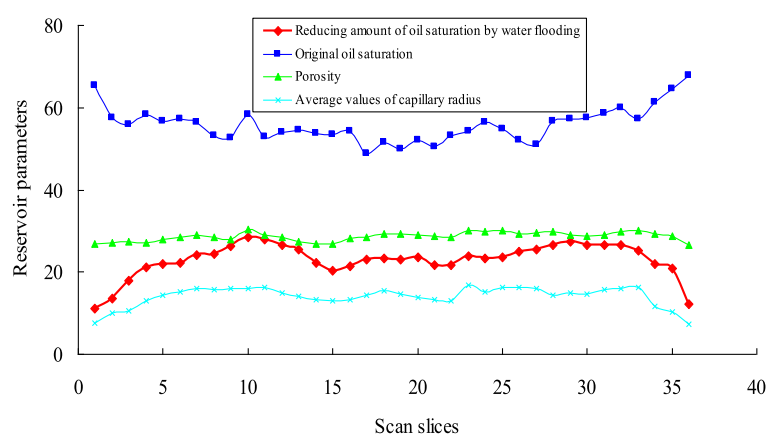

(A)

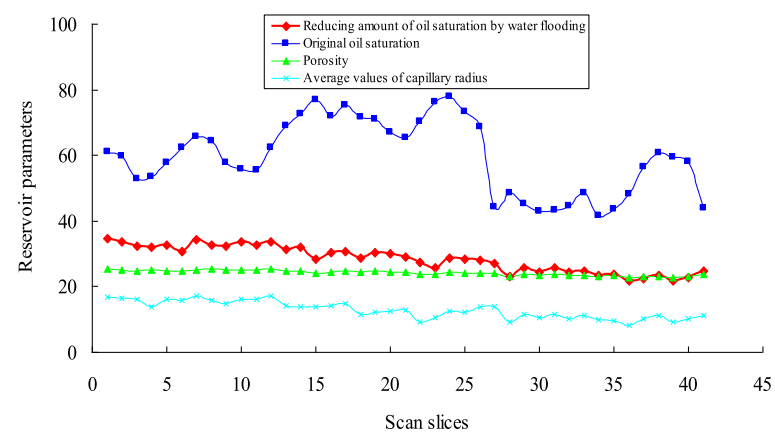

(B)

Fig. 10. Influence of oil displacement efficiency of conglomerate samples during water flooding process. (A) Hydrophilic sample; (B) Weak lipophilic sample.

hydrophilic and lipophilic conglomerate reservoirs, two oil recovery models could be established which are able to provide dynamic production parameters for final oil production prediction.

\subsection{Factor analysis of oil displacement efficiency}

\subsubsection{Water flooding process}

The micro experiment of water displacement seepage mechanism indicates that the injection water flows along the rock particle surface in a "scrawl" pattern for hydrophilic samples, the pore structure of complex modal and the seepage system of "sparse reticular and non reticular" lead to following features such as severe heterogeneity and larger displacement resistance effect which the largest displacement pressure achieves 27.65 MPa during water flooding oil process. Because of above reservoir features and seepage mechanism, the remaining oil after water flooding mainly distributes in form of film throat, pore intercross and large pores by surrounding small pores. However, for the weak lipophilic rock, the injection water flows in inrushing pattern which enters the rock through the central and forms an oil film on the surface of pore wall. Therefore, the remaining oil after water flooding mainly distributes on the particle surface, slim throats and non-displacement end of pore-throat in the form of the oil film. It can be found that although the water displacement mechanisms for hydrophilic rock are totally different from for the lipophilic rock, the distribution features of residual oil after water flooding in both cases are close related to the pore structures. Therefore, the water displacement oil efficiency is not only affected by the reservoir properties and oil saturation, but also controlled by pore structures. For a purpose of describing the reservoir pore structure, the average value of capillary radius is selected as the quantitative evaluation parameter. From the Figure 10, we can see that no matter for hydrophilic rock or lipophilic rock, the axial distribution of reducing amount of oil saturation by water flooding is mostly related to the changing trend of average capillary radius, secondly related to porosity and lastly related to original oil saturation. Thus, under the same external conditions, the reservoir pores structure is the dominant controlling factor of water flooding oil recovery for conglomerate, while reservoir properties and oil-bearing condition have a smaller impact on the water flooding oil recovery.

\subsubsection{Polymer flooding process}

The micro seepage mechanism experiment of polymer displacement reveals that for hydrophilic rocks, the polymer solution flows along the pore wall and drags the residual oil after water flooding into smaller droplets because of the higher shear stress between polymer solution and oil than the stress between water and oil. The higher viscosity of oil-water interface caused by polymer solution can make oil droplets highly transformable, which helps droplets to easily pass through slim throats with polymer solution and further enhance oil recovery. For weak lipophilic rocks, polymer solution mainly flows in inrushing seepage pattern which the polymer solution flows along the pore central while the crude oil flows along the pore wall. Because of the higher shear stress between polymer solution and oil than shear stress between water and oil, then the oil films attached to the pore walls are carried away by polymer solution from the particle surface in forms of bridge connection and forming oil silk. It can be found that the micro seepage mechanisms between water displacement and polymer displacement are totally different in the aspect of the much smaller impacts from pore structure condition on polymer displacement than on the water displacement. Figure 11 indicates that no matter for hydrophilic rock or weak lipophilic rock, there is not a good correlation between the average capillary radius or porosity and the axial reducing amount of oil saturation by polymer flooding, the correlation coefficients of hydrophilic sample are respectively $62.4 \%$ and $57.2 \%$ and the correlation coefficients of weak lipophilic sample are respectively $67.5 \%$ and $60.2 \%$. While there is a good positive correlation between the remaining oil saturation after water flooding and them, the correlation coefficients of hydrophilic sample and weak lipophilic sample reach respectively $80.6 \%$ and $90.8 \%$. The main reason caused above rule is what the polymer solution change shear stress of different fluid interfaces to displace effectively remaining oil after water flooding which exist in film throats, pore intercross, large pores by surrounding small pores and attaching particle 


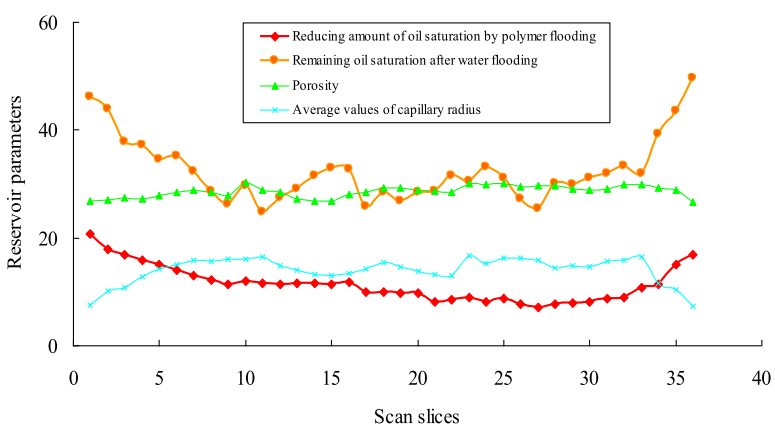

(A)

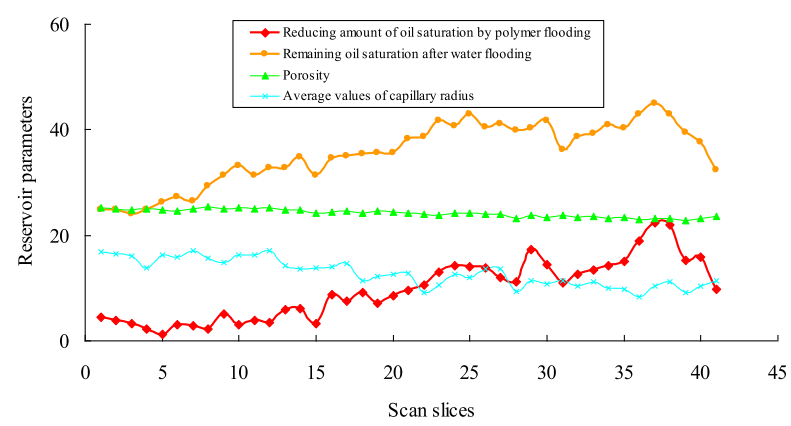

(B)

Fig. 11. Influence of oil displacement efficiency of conglomerate samples during polymer flooding process. (A) Hydrophilic sample; (B) Weak lipophilic sample.

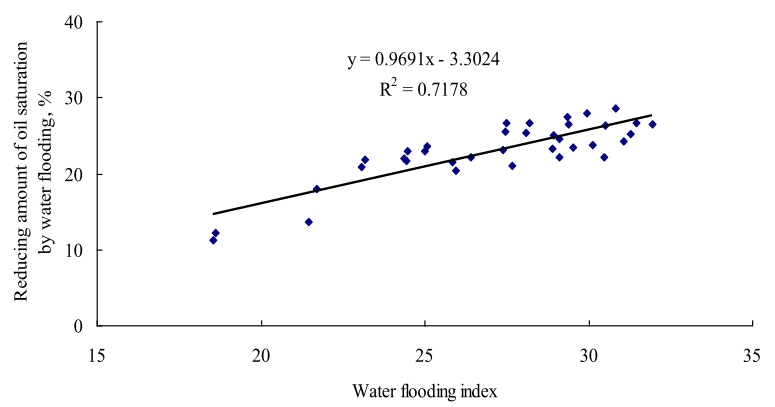

(A)

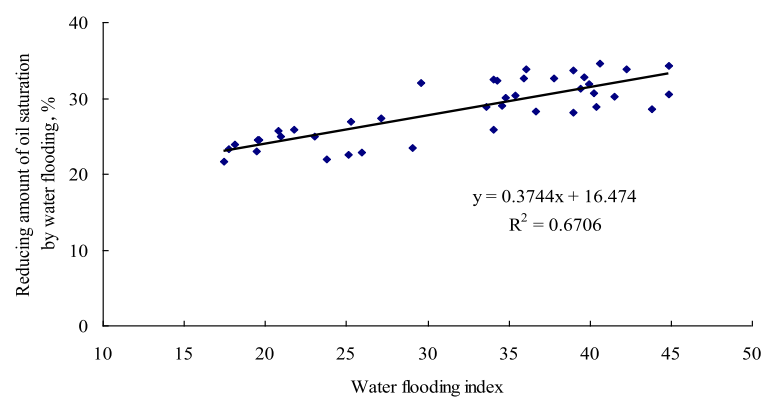

(B)

Fig. 12. Crossplots of water flooding index and reducing amount of oil saturation by water flooding. (A) Hydrophilic sample; (B) Weak lipophilic sample.

surface with oil film, but there is no residual oil in all the advanced seepage channels. As a result, the polymer displacement process mainly works in the residual oil enrichment not affecting much by the pore structure condition. To summarize, there is a good correlation between the reducing amount of oil saturation by polymer flooding and the remaining oil saturation after water flooding for conglomerate reservoir.

\subsection{Establishment of oil recovery models}

\subsubsection{Oil recovery models for water flooding stage}

For the hydrophilic rock and lipophilic rock of conglomerate reservoir, the water displacement oil efficiency is firstly controlled by pore structures, secondly by reservoir properties and oil-bearing conditions. The water flooding index is established to quantitatively evaluate impacts on water displacement oil efficiency from three parameters such as porosity, original oil saturation and average capillary radius. The formula is as following:

$$
W_{\mathrm{di}}=r \times \frac{S_{\mathrm{o}}}{\phi},
$$

where $W_{\mathrm{di}}$ - water flooding index, dimensionless; $r$ - average capillary radius, $\mathrm{mm} ; S_{\mathrm{o}}$ - original oil saturation, $\% ; \phi$ - effective porosity, $\%$.
The water flooding index includes following reservoir information such as original oil saturation, effective porosity and pore structure, its physical meaning is what the oil saturation under porosity unit occupy the size of capillary radius and its higher value indicate that the oil saturation of effective seepage is more larger in reservoir pore, under the same external conditions the two production parameters of reducing amount of oil saturation by water flooding and water flooding oil recovery are also higher. Figure 12 indicates that no matter for hydrophilic rock and weak lipophilic rock in conglomerate reservoir, the reducing amount of oil saturation by water flooding increase with water flooding index increasing and there is a good positive relationship between them which the correlation coefficient can achieve above 0.8 . Therefore, this parameter is able to effectively predict oil recovery of conglomerate reservoir in water flooding stage. Approaches for calculating original oil saturation can be referenced from related papers (Liu et al., 2015; Tan et al., 2013). The calculation model of reducing amount of oil saturation by water flooding is in Table 1 and the model of final oil recovery by water flooding is as follows:

$$
\mathrm{EOR}_{\mathrm{wf}}=\frac{\Delta S_{\mathrm{wfo}}}{S_{\mathrm{o}}} \times 100 \%
$$

where $\mathrm{EOR}_{\mathrm{wf}}$ - water flooding oil recovery, $\% ; S_{\mathrm{o}}$ - original oil saturation, $\% ; \Delta S_{\mathrm{wfo}}$ - reducing amount of oil saturation by water flooding, $\%$. 
Table 1. Calculation models of reducing amount of oil saturation for different displacement methods.

\begin{tabular}{llll}
\hline Reservoir type & \multicolumn{1}{c}{ Wettability } & $\begin{array}{c}\text { Models of reducing amount of oil } \\
\text { saturation by water flooding }\end{array}$ & $\begin{array}{c}\text { Models of reducing amount of oil } \\
\text { saturation by polymer flooding }\end{array}$ \\
\hline Conglomerate & Hydrophilic rock & $\Delta S_{\text {wfo }}=0.9691 \times W_{\text {di }}-3.3024$ & $\Delta S_{\text {pfo }}=4.4583 \times \mathrm{e}^{0.0274 \times S_{\text {wor }}}$ \\
reservoir in Kexia group & Weak lipophilic rock & $\Delta S_{\text {wfo }}=0.3744 \times W_{\mathrm{di}}+16.474$ & $\Delta S_{\text {pfo }}=0.1476 \times \mathrm{e}^{0.1118 \times S_{\text {wor }}}$ \\
\hline
\end{tabular}

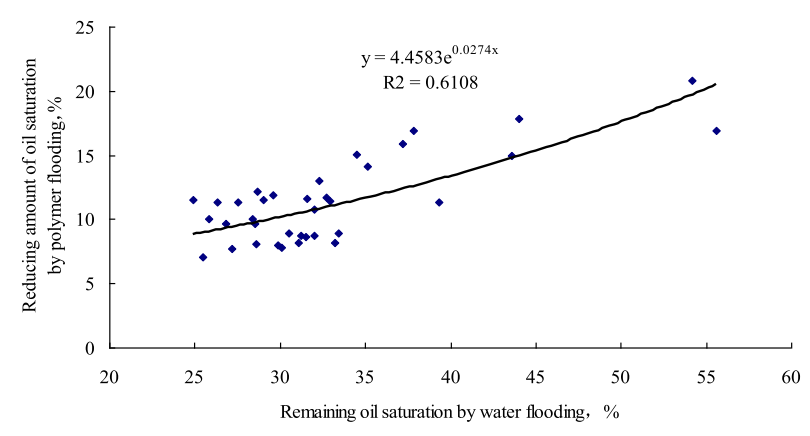

(A)

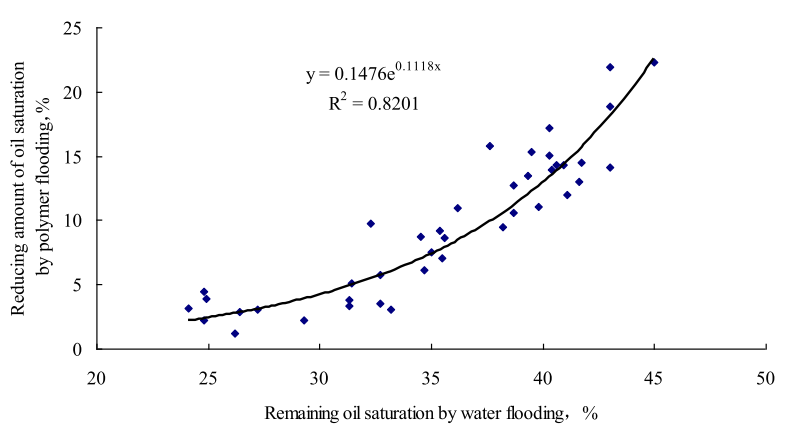

(B)

Fig. 13. Crossplots of remaining oil saturation by water flooding and reducing amount of oil saturation by polymer flooding. (A) Hydrophilic sample; (B) Weak lipophilic sample.

\subsubsection{Oil recovery models for polymer flooding stage}

Due to the significant difference of micro seepage mechanism between polymer displacement and water displacement, the pore structure has much less influence on the polymer solution than the water during the displacing process (Youssef et al., 2015). As a result, no matter for hydrophilic rock and lipophilic rock in conglomerate reservoir, the reducing amount of oil saturation by polymer flooding shows a good exponent correlation with remaining oil saturation by water flooding (Fig. 13), but not closely correlated with the changing trend of pore structure. This correlation can be used to establish calculation models for reducing amount of oil saturation by polymer flooding which helps to determine the calculation models of final oil recovery in polymer flooding stage and the oil recovery formula is as follows:

$$
\mathrm{EOR}_{\mathrm{pf}}=\frac{\Delta S_{\mathrm{pfo}}}{S_{\mathrm{o}}} \times 100 \%,
$$

where $\mathrm{EOR}_{\mathrm{pf}}$ - polymer flooding oil recovery, $\% ; S_{\mathrm{o}}$ - original oil saturation, $\%$; $\Delta S_{\text {pfo }}-$ reducing amount of oil saturation by polymer flooding, $\%$.

\subsection{Application effect of oil recovery models}

Under the constant external injection condition, the oil recovery in both water flooding and polymer flooding stages could be calculated respectively based on two parameters such as the water flood index and the remaining oil saturation by water flooding, then the final oil recovery under two displacement methods also could be achieved based on the formula $\mathrm{EOR}=\mathrm{EOR}_{\mathrm{wf}}+\mathrm{EOR}_{\mathrm{pf}}$. By applying this formula together with well logging curves and core analysis data, the oil recovery controlled by signal well range can be calculated effectively. Based on these oil recoveries, interpolation methods could be applied to achieve the oil recovery of whole reservoir in different displacement stages and the final oil recovery of the conglomerate reservoir. Compared to traditional oil recovery prediction methods, this method has a higher computational accuracy and is able to provide the oil recovery in different well pattern area which satisfies the requirements of development programs towards the changing reservoir features. These features of calculation models make it possible to generate a more accurate and reasonable displacing oil program for those conglomerate reservoirs with severe heterogeneity. In the purpose of comparing the calculation results, the traditional oil recovery prediction methods and the oil recovery models established in this research are applied on Kexia group reservoir in No. 1 Area of East 7th Block for both water flooding and polymer flooding stages. For the oil recovery in water flooding stage, the prediction results from Influenza A waterflooding curve method, Production declining method and Shearkachev method are $44.7 \%, 44.5 \%$ and $46.3 \%$ respectively comparing to the $44.9 \%$ from establishment oil recovery model. For the oil recovery in polymer flooding stage, the prediction result from numerical simulation is $66.8 \%$ while the result from establishment model is $67.4 \%$ (Tab. 2). By comparing these results above, it could be concluded that the prediction results from establishment models match well with the results from traditional methods. Thus, the establishment oil recovery models could be applied to predict final oil recovery of the conglomerate reservoir and further to 
Table 2. Comparison table of oil recovery prediction results.

\begin{tabular}{|c|c|c|c|c|c|c|c|}
\hline \multirow[t]{2}{*}{$\begin{array}{l}\text { Geological } \\
\text { reserves } \\
\left(10^{4} \mathrm{t}\right)\end{array}$} & \multicolumn{4}{|c|}{$\begin{array}{l}\text { Prediction values of water flooding oil } \\
\text { recovery based on traditional } \\
\text { methods }(\%)\end{array}$} & \multirow{2}{*}{$\begin{array}{c}\text { Prediction value } \\
\text { of water flooding } \\
\text { oil recovery based } \\
\text { on calculation } \\
\text { model } \\
(\%)\end{array}$} & \multirow{2}{*}{$\begin{array}{l}\text { Prediction value } \\
\text { of polymer } \\
\text { flooding oil } \\
\text { recovery based } \\
\text { on numerical } \\
\text { simulation } \\
(\%)\end{array}$} & \multirow{2}{*}{$\begin{array}{c}\text { Prediction value } \\
\text { of polymer flooding } \\
\text { oil recovery based } \\
\text { on calculation } \\
\text { model } \\
(\%)\end{array}$} \\
\hline & $\begin{array}{c}\text { Influenza A } \\
\text { waterflooding } \\
\text { curve method }\end{array}$ & $\begin{array}{l}\text { Production } \\
\text { declining } \\
\text { method }\end{array}$ & $\begin{array}{l}\text { Shearkachev } \\
\text { method }\end{array}$ & $\begin{array}{c}\text { Average } \\
\text { value }\end{array}$ & & & \\
\hline 1010 & 44.7 & 44.5 & 46.3 & 45.2 & 44.9 & 66.8 & 67.4 \\
\hline
\end{tabular}

provide more accurate geology parameters for reasonable design of displacement oil program.

\section{Conclusion}

1. The seepage mechanisms of water flooding and polymer flooding for hydrophilic rock are all mainly "crawling" displacement along rock surface. The residual oil distributed fine throats and pore interchange after water flooding are cut into a lot of small droplets by the stronger shearing drag effect of polymer solution, then pass well narrow throats to move forward along with polymer solution flowing to achieve the enhanced oil recovery purpose.

2. The seepage mechanisms of water flooding and polymer flooding for weak lipophilic rock are all mainly "inrushing" displacement along pore central. For the residual oil distributed rock particle surface in form of oil film and fine pore-throat, polymer solution with stronger shear stress make these oil film to displacing away from particle surface by two kinds of ways such as bridging communication and forming oil silk.

3. The impact of CMPS on polymer solution displacement and its seepage is much smaller than water flooding solution for conglomerate reservoir. Therefore, the pore structure is the main controlling factor of water flooding efficiency for hydrophilic rock and weak lipophilic rock, the other factors such as reservoir properties and oil saturation are smaller. Because the nature between polymer solution and injection water solution has essential differences, the polymer flooding efficiency is the best correlation with residual oil saturation after water flooding. Based on above research results, the calculation models of oil recovery in water flooding stage and polymer flooding stage are established respectively to forecast final oil recovery of conglomerate reservoir.

Acknowledgments. This research was supported by PetroChina Innovation Foundation (No. 2018D-5007-0103) and Young Teacher's Research Starting Foundation of University of Chinese Academy of Sciences (No. 55103BY00).

\section{References}

Alishaev M.G., Belyanin G.N. (1999) Influence of gravitational segregation on oil-water displacement efficiency in thick fractured reservoir, Nefty. Khozy. 10, 6, 21-23.

Batenburg V.D.W., Oedai S. (2013) Visualisation of light oil mobilisation in ASP core floods using X-ray CT imaging, SPE Enhanced Oil Recovery Conference, Kuala Lumpur, Malaysia.

Buchgraber M., Clemens T., Castanier L.M., Kovscek A.R. (2011) A microvisual study of the displacement of viscous oil by polymer solutions, SPE Reserv. Evalu. Eng. 14, 3, 269-280.

Dullien F.A.L. (1979) Porous media: Fluid transport and pore structure, Academic Press, New York.

Editorial Board of Science and Technology Books in Daqing Oilfield (1998) Enhanced oil recovery technologies, Petroleum Industry Press, Beijing.

Feng H.J., Nie X.B., Xu G.Y., Li R.H., Liu W.D. (2007) Microscopic mechanisms of oil displacement by polymer solution for conglomerate reservoir, Oilfield Chem. 24, 3, 232-237.

Jiang X.L., Wang R.L., Lu X.G., Deng Q.J., Xiao L. (2014) Experimental study on the reservoir adaptability of polymer molecular weight, Oilfield Chem. 31, 2, 269-273.

He H., Song X.M., Jiang Y.W., Peng S.M., Li Y.L., Sun J.M. (2012) Heterogeneity of sandy conglomerate reservoir and its influence on remaining oil distribution: A case study from Badaowan foramtion in the mid-west of block 2 in Karamay oilfield, Lithol. Reserv. 24, 2, 117-122.

Hu F.T., Li L.W., Liu S.S. (1997) Development model of conglomerate reservoir, Petroleum Industry Press, Beijing.

$\mathrm{Hu}$ X.D., Lv J.R., Cheng H.J., Guo Q.Z. (2014) Analysis on changeable rules of remaining oil in conglomerate reservoir after polymer flooding, Xinjiang Oil Gas 10, 3, 51-56.

Hua Z., Li M.Y., Ni X.X., Wang H.Y., Yang Z.H., Lin M.Q. (2016) Effect of injection brine composition on wettability and oil recovery in sandstone reservoirs, Fuel 182, 687-695.

Li H.B., Chen Z.H. (2006) Characteristics of interfacial tension and oil displacement efficiency with alkaline-surfactantpolymer flooding technology, Acta Petrol. Sin. 27, 5, 96-98.

Li Q.C., Wu M., Zhao L.C. (1997) Conglomerate oilfield development, Petroleum Industry Press, Beijing.

Li P.H., Li Z.M., Zhao J.S., Li B.F., Li P.C. (2010) Experimental study on multi-slugs parallel gathering energy for enhancing oil recovery after polymer flooding, Acta Petrol. Sin. 31, 1, 110-113.

Liu W.D., Tong Z.X., Xu G.Y., Nie X.B., Li R.H. (2008) A study on conformity of polymers to pore size in conglomerate oil reservoirs, Oilfield Chem. 25, 3, 241-244. 
Liu G., Hou J.R., Qiu S.P., Lin M.Q., Li M.Y., Hao H.D., Sun L.L. (2014) Matching relationship between polymer molecular size and pore throat of conglomerate reservoir, Fault-Block Oil Gas Field 21, 6, 771-774.

Liu R.Q., Duan Y.G., Tan F.Q., Wang G.C., Qin J.H., Bhupati N. (2015) Evaluating on original resistivity inversion method of water flooding conglomerate reservoir based on petrophysics analysis, J. Geophys. Eng. 12, 5, 780-792.

Luo M.G. (1991) Quantitative models of reservoir structure modal for clastic reservoir, Acta Petrol. Sin. 12, 4, $27-37$.

Luo M.G., Zhang T.H. (1992) Micropore structure and classification of conglomerate reservoir formation in Karamay oilfield, Oil Gas Geol. 13, 2, 201-209.

Meybodi H.E., Kharrat R., Araghi M.N. (2011) Experimental studying of pore morphology and wettability effects on microscopic and macroscopic displacement efficiency of polymer flooding, J. Pet. Sci. Eng. 78, 2, 347-363.

Tan F.Q., Li H.Q., Xu C.F., Li Q.Y., Peng S.C. (2010) Quantitative evaluation methods for water-flooded layers of conglomerate reservoir based on well logging data, Petrol. Sci. 7, 4, 485-493.

Tan F.Q., Li H.Q., Sun Z.C., Ouyang M. (2013) Identification of natural gas fractured volcanic formation by using numerical inversion method, J. Pet. Sci. Eng. 80, 3, 85-97.

Wang S.Y., Huang Y.B., Pereira V., Gryte C.C. (1985) Application of computed tomography to oil recovery porous media, Appl. Opt. 24, 23, 4021-4027.
Wang D.M., Cheng J.C., Wu J.Z., Wang G. (2005) Application of polymer flooding technology in Daqing Oilfield, Acta Petrol. Sin. 26, 1, 74-78.

Wegner J. (2015) Investigation of polymer enhance oil recovery in microfluidic devices that resemble porous media-an experimental and numerical approach, Oil Gas Eur. Mag. 41, 3, 137-142.

Wei Y.J., Li D.S., Hu S.Y., Lei Z.Y., He D.F. (2007) Fans sedimentation and exploration direction of fan hydrocarbone reservoir in foreland thrust belt of the northwestern Junggar basin, Acta Petrol. Sin. 28, 1, 62-71.

Wellington S.L., Vinegar H.J. (1987) X-ray computerized tomography, J. Pet. Technol. 39, 8, 885-898.

Xu S.Y., Zhu L.Z., Wang D.J. (2005) Dynamic simulation and evolvement model for microscopic remaining oil, Acta Petrol. Sin. 26, 2, 69-72.

Xu C.F., Liu H.X., Qian G.B., Qin J.H. (2011) Microcosmic mechanisms of water-oil displacement in conglomerate reservoir in Karamay oilfield, NW China, Petrol. Explor. Dev. 38, 6, 725-732.

Youssef S., Oughanem R., PeyssonY., Bauer D., Vizika O. (2015) Mobilization of trapped oil by surfactant injection-an experimental study using multi-scale imaging, IOR - 18th European Symposium on Improved Oil Recovery, 14-16 April, Dresden, Germany.

Zhu S.Q., Qian G.B., Liu S.S. (2015) Secondary development of conglomerate reservoir in Karamay oilfield, Petroleum Industry Press, Beijing. 